\title{
New Insight into Wild Red Raspberry Populations using Simple Sequence Repeat Markers
}

\author{
Julie Graham¹, Mary Woodhead, Kay Smith, Joanne Russell, Bruce Marshall, Gavin Ramsay, \\ and Geoff Squire \\ Scottish Crop Research Institute, Invergowrie, Dundee, DD2 5DA, United Kingdom
}

\begin{abstract}
AdDitional INDEX words. Rubus idaeus, SSR, gene flow, conservation
Abstract. Scottish wild red raspberry (Rubus idaeus) plants at 12 sites were re-examined 10 years after initial studies had been carried out to examine the decline in population size and to address an earlier finding that demonstrated significant population differentiation over a small scale. Ten simple sequence repeat (SSR) loci were screened on the plants and a total of 80 alleles were detected, half of which were unique to a particular population, with all populations containing unique SSR alleles. Only 18 of the 80 alleles present in the wild were found in cultivated raspberries, highlighting the genetic diversity available for future breeding. This finding makes the decline in population number observed a concern, as this unique diversity is being eroded, primarily due to human impact. An additional 17 unique alleles were identified in the cultivars that were not present in the wild individuals studied. Gene flow into one lowland site was identified by the gain of one new allele into progeny at the site, but three alleles were also lost from parents to progeny. SSR markers were used to estimate the levels of outcrossing in wild red raspberry for the first time, and confirmed that the populations studied were outcrossing, intermating populations. The nonsignificant global $F_{\text {IS }}$ value indicates that red raspberry is an outbreeder (global $F_{\text {IS }}=-0.117$ ), but significant population differentiation was observed [global $F_{\mathrm{ST}}=0.348(P<0.001)$ ]. Diversity in this crop's wild relative and the population differentiation observed may have use in the future for breeding aimed at addressing climate change scenarios, and consideration should be given to means of conserving the diversity revealed by these studies.
\end{abstract}

Red raspberry (Rubus idaeus) is cultivated on a large scale and has frequent sympatric wild populations in the Tayside area of the United Kingdom. The high potential for gene flow between these populations has encouraged the study of the interactions among wild and cultivated forms of a species (Graham et al., 1997, 2003; Marshall et al., 2001). These studies have revealed that the wild red raspberry exists as a series of local populations that are differentiated genetically and physiologically, and that the physiological differences are maintained in common environments (Graham et al., 2003; Marshall et al., 2001). The wild plants are also genetically distinct from cultivated raspberries (Graham et al., 2003). The populations vary greatly in size from those with only a few plants to those with hundreds of plants and whether they have been observed to be expanding or in decline over a 10 -year period of study. The decline generally observed, resulting mainly from habitat degradation, may lead to erosion of genetic diversity and increased interpopulation genetic divergence (Young et al., 1996), which, in the long term, may affect the viability of populations, reducing their ability to respond to changing selection pressures (Young et al., 1996). In light of current concern over the impact of climate change on fruit crops such as lack of winter chill reducing budbreak (R. Brennan, personal communication) and delayed flowering (Legave et al., 2008), coupled with the demonstration from previous studies that these wild red raspberry populations exhibit significant variation in

Received for publication 20 Aug. 2008. Accepted for publication 30 Oct. 2008. This work was funded by The Scottish Executive Rural Affairs Department. The authors gratefully acknowledge Jim McNicol (BioSS) and Wendy McGavin (SCRI) for carrying out ELISAs, Dave Cooke (SCRI) for pot tests, and Jane Squirell (Royal Botanic Garden Edinburgh) and Ian Dawson for critical reading of the manuscript.

${ }^{1}$ Corresponding author. E-mail: Julie.Graham@scri.ac.uk. key physiological traits (Marshall et al., 2001), information on changes in the wild red raspberry populations over time has important practical relevance for the conservation of these populations and for the use of wild germplasm in plant breeding programs.

The genetic similarity within specific populations and the distinctness between them has been determined previously by RAPD markers (Graham et al., 1997, 2003), and suggests that there are strong limitations to gene flow through pollen and seed movement. Clonal growth via root sucker production and selfpollination are known to occur in wild $R$. idaeus (Jennings, 1988), but it is generally considered an outbreeding species (Keep, 1972). Wind-, insect-, bird-, and mammal-mediated movement of genes by pollen and seeds are likely, possibly over large distances, which can potentially generate high levels of gene flow and little population structuring. The restricted pollen movement between the wild populations, and between them and the large blocks of cultivated red raspberry grown near the lowland wild populations, has been partly explained by a lack of overlap in flowering period (Graham et al., 2003). Similarly, some hindrance, yet to be determined, must also exist to gene movement from seeds. Possibly, seed germination in the wild is very low or variable or seeds have extended dormancy requirements (Granstrom, 1987). This population structuring may also be explained by habitat loss and the resulting increasing interpopulation genetic divergence (Lowe et al., 2005).

Definitive evidence on gene flow between the populations is still lacking. The RAPDs used previously were suitable for detecting natural variation (Graham et al., 1997, 2003), but are mostly dominantly inherited and are considered an imprecise method for assessing gene flow. SSR (or microsatellites), in contrast, are multiallelic, highly polymorphic, robust, codominant DNA markers (Powell et al., 1996) that have been used to examine genetic diversity at the population level in a wide 
range of taxa (Estoup et al., 1998; FitzSimmons et al., 1995; Paetkau et al., 1995; Perera et al., 2000; Simonsen et al., 1998; Vendramin et al., 2000). These markers provide a tool for directly assessing pollen dispersal and effective gene flow by progeny typing (Dawson et al., 1997) and for studying habitat effects on genetic resources (Lowe et al., 2005). With the development of SSR markers in red raspberry (Graham et al., 2002, 2004, 2006), it is now possible to examine specific loci for genetic polymorphisms and measure gene flow directly in the form of new alleles entering a population. Codominant markers such as SSRs also permit accurate estimates of the degree of heterozygosity within populations and so may also be used to indicate the breeding system of the plant (Ritland, 1986; Ward et al., 2005).

The aim of this work was to provide a picture of the changes in wild red raspberry populations in the Tayside region of the United Kingdon 10 years after the initial survey, and to develop a greater understanding of population genetic diversity and gene flow among the populations.

\section{Materials and Methods}

Population surveys. The 12 wild red raspberry populations surveyed were those previously described as Site 1 to Site 12 (Graham et al., 2003), details of which are shown in Table 1. One wild population (Site 12) with 46 individuals was selected for the study of all individuals, being of moderate size, situated within an area of commercial red raspberry cultivation, and close to other wild populations. The populations were visited during the growing season. Numbers were determined by counting plants in the smaller populations or, for the larger populations, by counting within a set area at each site and then estimating plant numbers. The period during which flowers were open was recorded. The extent of root sucker production from each population was visually assessed, as described by Graham et al. (2004). Seed germination was assessed at Site 12 by counting the number of seeds collected from the fruit for each of the 46 plants and recording the number of seeds that germinated (as described below). Progeny arrays were constructed by bulking DNA from all seedlings germinated per parent plant at Site 12 .

Seed collection, treatment, and Germination. All red fruit was collected from the population at Site 12. Seeds were extracted from the flesh of the fruit by squashing onto filter paper discs, drying at room temperature for 6 weeks, and then scraping the seeds from the pulp. Seeds were then bagged, stored in damp sand in polythene bags, and stored at 0 to $5{ }^{\circ} \mathrm{C}$ for 6 weeks before being counted and sown in seed trays. Viable seeds from different parent plants were sown in separate trays in sand and placed at $4{ }^{\circ} \mathrm{C}$ for 20 weeks before being moved to a warm glasshouse $\left(20^{\circ} \mathrm{C}\right.$ day $/ 15^{\circ} \mathrm{C}$ night $)$ for germination.

Plant material and DNA isolation. Expanding leaves were collected from healthy individuals at Sites 1 to 12, bagged, frozen in liquid nitrogen at the site, and then stored at $-80{ }^{\circ} \mathrm{C}$ until required. DNA was extracted as described previously by Graham et al. (2003). If less than 10 plants were available at the site, leaves were collected from all samples where high-quality young leaf material was available. For populations greater than 10 plants, 12 samples were collected again where leaves were of sufficient quality for DNA extraction.

After germination, leaves were collected from all seedlings at Site 12 and were used for DNA isolation. Due to the large seedling numbers (279) produced, progeny arrays were produced by bulking DNA from the germinated seedlings from each parent for SSR analysis.

DNA was also isolated from leaves from five commercial, clonally propagated, red raspberry cultivars: Glen Clova (released in 1969 and widely grown commercially); Glen Moy, Glen Prosen, and Glen Lyon [the first spine-free cultivars released in the early 1980s (Jennings, 1988) of which Glen Moy was the most important commercially]; and Glen Ample [the most recently released (1998) widely grown cultivar].

SSR SCREENING AND DATA ANALYSIS. Ten previously mapped SSR loci [Rub1a, 4a, 25a, 26a, 108a, 157b, 223a, 228a, 262b, and 277a (Table 2) (Graham et al., 2002, 2004, 2006)] were studied in 117 individuals from the 12 different populations

Table 1. Plant numbers, location, altitude, and flowering time status of the 12 Scottish wild Rubus idaeus populations studied from 1996 to 2006.

\begin{tabular}{|c|c|c|c|c|c|}
\hline Site & $\begin{array}{c}\text { Plants in } 1996 \\
\text { (approximate no.) }\end{array}$ & $\begin{array}{c}\text { Plants in } 2006 \\
\text { (approximate no.) }\end{array}$ & $\begin{array}{c}\text { Population } \\
\text { name }^{z}\end{array}$ & $\begin{array}{l}\text { Altitude } \\
(\mathrm{m})\end{array}$ & $\begin{array}{l}\text { Flowers open } \\
\text { (d from } 1 \text { Apr.) }\end{array}$ \\
\hline 1 & Unknown & 2 & Glen Doll & 600 & $>70$ \\
\hline 2 & 16 & 10 & Glen Doll & 600 & $>70$ \\
\hline 4 & 200 & $50^{y}$ & Clova A & 250 & $56-70$ \\
\hline 5 & 200 & $>500^{x}$ & Clova B & 250 & $49-56$ \\
\hline 6 & 5 & 2 & Glen Clova & 250 & $49-56$ \\
\hline 9 & 400 & $10^{\mathrm{u}}$ & Kirriemuir & 60 & $35-42$ \\
\hline 10 & 200 & $11^{\mathrm{t}}$ & Knapp & 100 & $35-<42$ \\
\hline 11 & 400 & 200 & Kingoodie & 5 & $28-<35$ \\
\hline 12 & 150 & $46^{\mathrm{t}}$ & Longforgan & 5 & $28-<35$ \\
\hline
\end{tabular}

${ }^{\mathrm{z} F r o m ~ M a r s h a l l ~ e t ~ a l . ~(2001) . ~}$

${ }^{\mathrm{y}}$ Small number of root suckers produced for new cane.

${ }^{x}$ Large number of root suckers produced.

wNo fruit development.

${ }^{\vee}$ Large area removed for grazing.

"Land excavation.

'Land clearing. 


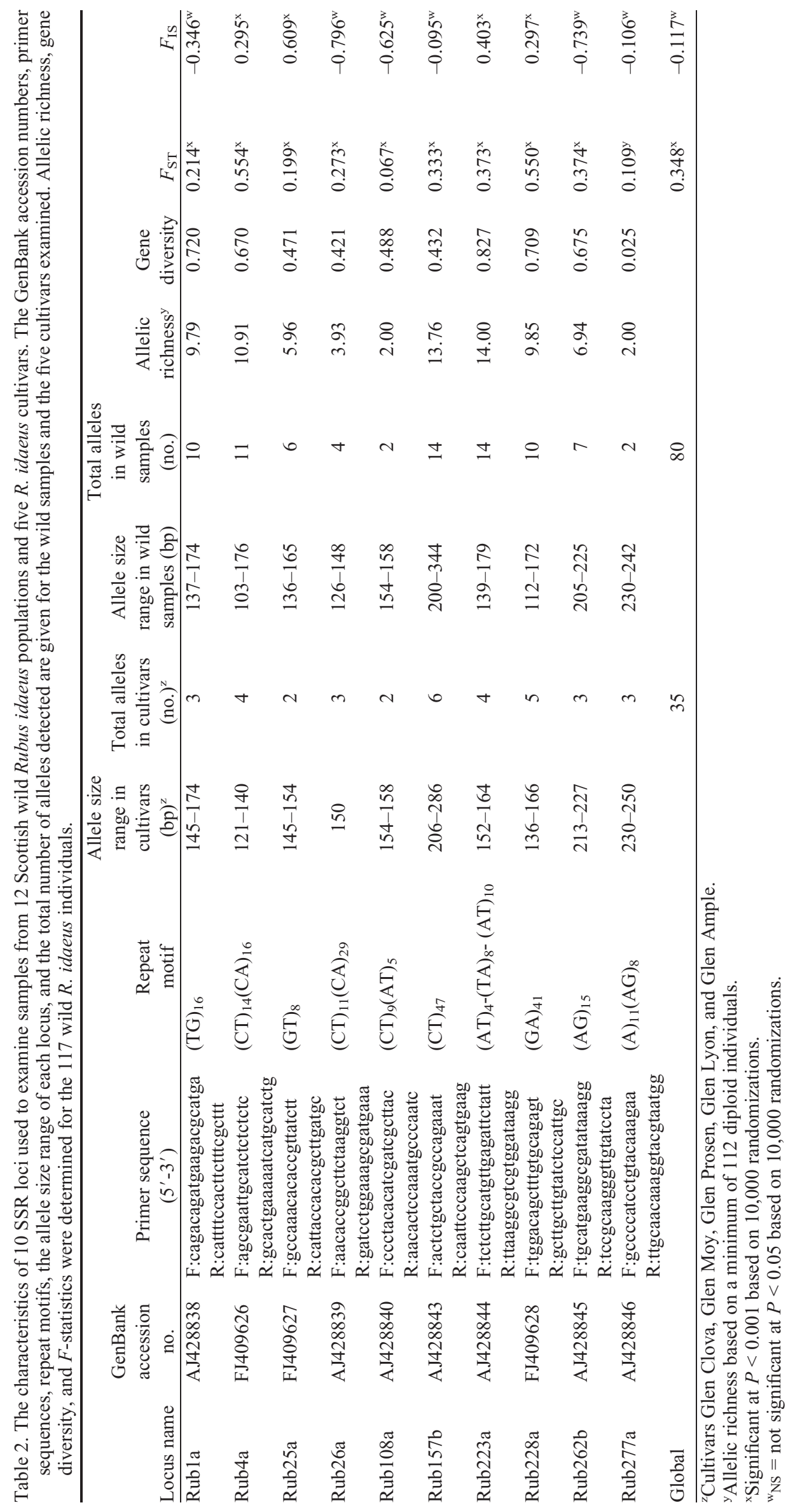


Table 3. Summary of the 12 Scottish wild Rubus idaeus populations surveyed using 10 SSR loci. The number of individuals studied, the mean number of alleles per locus $(A)$, the percentage of polymorphic loci, the number of private alleles, the number of multilocus genotypes, and the observed $\left(H_{\mathrm{O}}\right)$ and expected $\left(H_{\mathrm{E}}\right)$ heterozygosities are given for each population. The inbreeding coefficient $\left(F_{\mathrm{IS}}\right)$ values were calculated for populations with 10 or more individuals.

\begin{tabular}{|c|c|c|c|c|c|c|c|c|c|}
\hline $\begin{array}{l}\text { Population } \\
\text { no. }\end{array}$ & $\begin{array}{l}\text { Plants } \\
\text { available } \\
\text { for study } \\
\text { (no.) }\end{array}$ & $\begin{array}{c}\text { Mean } \\
\text { alleles } \\
\text { (no./locus) }\end{array}$ & $\begin{array}{c}\text { Polymorphic } \\
\text { loci } \\
(\%)\end{array}$ & $\begin{array}{c}\text { Private } \\
\text { alleles } \\
\text { (no.) }\end{array}$ & $\begin{array}{c}\text { Multilocus } \\
\text { genotypes } \\
\text { (no.) }\end{array}$ & $H_{\mathrm{O}}(\mathrm{SD})$ & $H_{\mathrm{E}}(\mathrm{SD})$ & $F_{\text {IS }}$ & $F_{\mathrm{ST}}$ \\
\hline 2 & 8 & 2.4 & 90.0 & 3 & 7 & $0.339(0.058)$ & $0.454(0.066)$ & N/A & \\
\hline 3 & 2 & 1.7 & 50.0 & 1 & 2 & $0.200(0.089)$ & $0.350(0.120)$ & N/A & \\
\hline 4 & 7 & 2.4 & 80.0 & 1 & 7 & $0.371(0.058)$ & $0.472(0.082)$ & N/A & \\
\hline 6 & 2 & 2.1 & 80.0 & 2 & 2 & $0.550(0.11)$ & $0.517(0.101)$ & $\mathrm{N} / \mathrm{A}$ & \\
\hline 7 & 3 & 2.4 & 80.0 & 2 & 3 & $0.433(0.091)$ & $0.520(0.101)$ & N/A & \\
\hline 8 & 12 & 2.7 & 70.0 & 2 & 11 & $0.275(0.041)$ & $0.347(0.097)$ & $0.215^{\mathrm{y}}$ & \\
\hline 9 & 10 & 2.5 & 90.0 & 4 & 8 & $0.546(0.059)$ & $0.501(0.051)$ & $-0.094^{z}$ & \\
\hline 10 & 3 & 3.9 & 90.0 & 2 & 3 & $0.667(0.088)$ & $0.553(0.075)$ & N/A & \\
\hline 11 & 11 & 2.3 & 100 & 12 & 11 & $0.547(0.049)$ & $0.562(0.055)$ & $0.028^{z}$ & \\
\hline
\end{tabular}

${ }^{\mathrm{z}}$ Not significant at $P<0.05$.

${ }^{y}$ Not significant at $P>0.01$.

${ }^{\mathrm{x}}$ Not significant at $P<0.001$.

(Table 3). A detailed gene flow study using the progeny from Site 12 was also carried out and the progeny were genotyped using the 10 mapped SSRs, allowing the identification of any new alleles in the progeny from other populations. Five extensively grown commercial red raspberry cultivars that represent about 40 years of commercial cultivation were also examined at these loci.

For each SSR locus, polymerase chain reactions (PCRs) were performed in $25-\mu \mathrm{L}$ reactions with $25 \mathrm{ng}$ of DNA, $2 \mu \mathrm{M}$ each primer, and $0.5 \mathrm{U}$ of Taq DNA polymerase enzyme (Roche, Mannheim, Germany) in a thermal cycler (GeneAmp PCR System 9700; Applied Biosystems, Warrington, UK) for 25 cycles with denaturation at $94^{\circ} \mathrm{C}$ for $45 \mathrm{~s}$, annealing at $59^{\circ} \mathrm{C}$ for $45 \mathrm{~s}$, and extension at $72{ }^{\circ} \mathrm{C}$ for $60 \mathrm{~s}$ with a final extension step at $72{ }^{\circ} \mathrm{C}$ for $5 \mathrm{~min}$. The forward primer of each primer pair (Table 2) was fluorescently end-labeled with 5-HEX, 6-FAM, or 5-TET, and PCR products were prepared according to Macaulay et al. (2001) for analysis on the ABI Prism 377 automated sequencer (Applied Biosystems). Allele sizes were determined using GENESCAN software program (Applied Biosystems) and GeneScan-350 (TAMRA; Applied Biosystems) as an internal size standard.

Sequence confirmation of alleles showing considerable size variation was performed on individuals homozygous at that locus. PCRs were carried out as described above except using nonlabeled primers and high-fidelity Taq DNA polymerase (Roche). Bands were excised from $2 \%$ agarose gels, eluted using a MinElute gel extraction kit (Qiagen, Crawley, UK), and sequenced using the dRhodamine terminator cycle sequencing reaction ready kit (Applied Biosystems) and analyzed using an ABI Prism 377 automated sequencer.

For each locus, allele frequencies were calculated using the Microsatellite toolkit (Park, 2001). Allelic richness (average number of alleles per locus), gene diversity (a measure of the heterozygosity of a subdivided population; Nei, 1973), and $F$ statistics (which describe deviations from random mating due to inbreeding $\left(F_{\mathrm{IS}}\right)$ and population differentiation $\left(F_{\mathrm{ST}}\right)$ ) were calculated using FSTAT (Goudet, 2002).

For all populations with equal to or more than 10 individuals, observed and expected heterozygosities were estimated using the Microsatellite toolkit, and $F$ statistics were calculated using FSTAT for populations with more than 10 individuals.

Individual and population distance matrices were calculated using Microsat (Stanford University, 2004). Phylogenetic trees were designed using the Neighbor program of PHYLIP, version 3.6 (Felsenstein, 2004), and were visualized by TreeView (Page, 1996).

Disease SCReening. Given the decline detected in most populations, a survey for the presence of two major diseases, the pollen borne raspberry bushy dwarf virus (RBDV) and the serious root pathogen Phytophthora fragaria var. rubi, was undertaken on all plants collected from all populations to determine whether these may impact on population viability. The presence of RBDV was screened for using ELISA (Jones et al., 1998) and presence of red raspberry root rot was assessed by visual symptom observation in the population on canes and after collection and propagation of root material. Wild root material collected from each mother plant was chilled for 6 weeks, after which the root was put in trays with compost and placed in a warm glasshouse. Plants growing from the root material served as a source for testing. The populations under study were also screened for susceptibility to root rot in pot tests to ensure detectable symptom development in the presence of the pathogen (Kennedy and Duncan, 1991).

\section{Results}

Population changes over time. The plants in these 12 populations have been studied over a 10-year period, during which time, the plant numbers in most of the populations have 
Table 4. Allele frequencies at 10 SSR loci in samples from 12 wild Rubus idaeus populations in Scotland.

\begin{tabular}{|c|c|c|c|c|c|c|c|c|c|c|c|c|}
\hline \multirow[b]{2}{*}{ Locus } & \multicolumn{12}{|c|}{ Population } \\
\hline & 1 & 2 & 3 & 4 & 5 & 6 & 7 & 8 & 9 & 10 & 11 & 12 \\
\hline \multicolumn{13}{|l|}{$\overline{\text { Rub1a }}$} \\
\hline 137 & 0.25 & & & & & & & & & & & \\
\hline 140 & & & 0.25 & & & & & & & & & \\
\hline 145 & 0.25 & 0.21 & & 0.28 & 0.27 & 0.25 & 0.33 & 0.54 & & 0.45 & 0.50 & \\
\hline 148 & & & & & & & & & & 0.09 & & \\
\hline 150 & 0.25 & 0.50 & 0.50 & 0.28 & 0.50 & 0.25 & 0.33 & 0.17 & 0.67 & 0.18 & 0.50 & 0.50 \\
\hline 156 & & & & & & & & 0.04 & & 0.05 & & \\
\hline 158 & & & & & & & & & & 0.05 & & \\
\hline 160 & 0.25 & 0.21 & 0.25 & 0.44 & 0.09 & 0.25 & 0.33 & 0.25 & 0.33 & 0.18 & & \\
\hline 166 & & 0.08 & & & & & & & & & & \\
\hline 174 & & & & & 0.14 & 0.25 & & & & & & 0.50 \\
\hline \multicolumn{13}{|c|}{ Rub25a } \\
\hline 136 & & & & 0.14 & & & & & & & & \\
\hline 145 & 0.75 & 0.42 & 1.00 & 0.29 & 0.41 & 0.75 & 0.50 & 0.91 & 0.65 & 0.80 & 0.33 & 0.83 \\
\hline 148 & & & & & & & & & & & & 0.12 \\
\hline 154 & 0.25 & 0.58 & & 0.57 & 0.59 & 0.25 & 0.50 & 0.09 & 0.20 & & 0.17 & \\
\hline 156 & & & & & & & & & 0.15 & 0.20 & 0.33 & 0.05 \\
\hline 165 & & & & & & & & & & & 0.17 & \\
\hline \multicolumn{13}{|c|}{ Rub157b } \\
\hline 200 & 0.25 & 0.25 & 0.25 & & & 0.50 & 0.17 & & 0.55 & & & \\
\hline 206 & 0.50 & 0.63 & 0.75 & 0.57 & 0.77 & 0.50 & 0.67 & 0.84 & 0.20 & 0.56 & 0.17 & 0.98 \\
\hline 224 & & & & & & & & & & & & 0.02 \\
\hline 227 & & & & & & & & 0.08 & & & & \\
\hline 232 & & & & & & & 0.16 & & & & 0.66 & \\
\hline 235 & & & & & & & & & & 0.32 & & \\
\hline 243 & & & & & & & & & & & 0.17 & \\
\hline 252 & 0.25 & 0.12 & & & & & & & & & & \\
\hline 254 & & & & 0.43 & 0.09 & & & 0.08 & & 0.04 & & \\
\hline 278 & & & & & & & & & & & & \\
\hline 284 & & & & & & & & & 0.25 & & & \\
\hline 295 & & & & & & & & & & 0.04 & & \\
\hline 320 & & & & & 0.14 & & & & & & & \\
\hline 344 & & & & & & & & & & 0.04 & & \\
\hline \multicolumn{13}{|c|}{ Rub262b } \\
\hline 205 & & & & & & & 0.17 & & & & & \\
\hline 211 & & & & 0.21 & 0.45 & & 0.33 & & & & & \\
\hline 213 & 0.25 & 0.29 & & & 0.05 & & & & 0.50 & 0.45 & & \\
\hline 219 & & 0.71 & 1.00 & 0.50 & 0.45 & 0.25 & 0.33 & 1.00 & & 0.55 & 0.50 & 0.48 \\
\hline 221 & & & & 0.08 & & & 0.17 & & 0.50 & & & \\
\hline 223 & 0.75 & & & 0.21 & 0.05 & 0.75 & & & & & & \\
\hline 225 & & & & & & & & & & & 0.50 & 0.52 \\
\hline \multicolumn{13}{|c|}{ Rub277a } \\
\hline 230 & 1.00 & 1.00 & 1.00 & 1.00 & 1.00 & 1.00 & 1.00 & 1.00 & 1.00 & 0.86 & 1.00 & 1.00 \\
\hline 242 & & & & & & & & & & 0.14 & & \\
\hline \multicolumn{13}{|l|}{ Rub4a } \\
\hline 103 & & 0.14 & & & & & & & & & & \\
\hline 112 & & 0.36 & & 0.29 & 0.18 & & 0.67 & 0.35 & & 0.05 & & \\
\hline 115 & 1.00 & 0.50 & 0.50 & 0.64 & 0.77 & 0.25 & 0.33 & 0.65 & 0.40 & 0.25 & 0.50 & 0.01 \\
\hline 125 & & & & & & & & & & 0.10 & & \\
\hline 128 & & & 0.50 & 0.07 & & & & & & 0.45 & 0.50 & 0.96 \\
\hline 136 & & & & & & 0.25 & & & & & & \\
\hline 140 & & & & & 0.05 & & & & & & & 0.02 \\
\hline 145 & & & & & & & & & & & & 0.01 \\
\hline 153 & & & & & & 0.50 & & & & & & \\
\hline 156 & & & & & & & & & 0.60 & & & \\
\hline 176 & & & & & & & & & & 0.15 & & \\
\hline
\end{tabular}


Table 4. Continued.

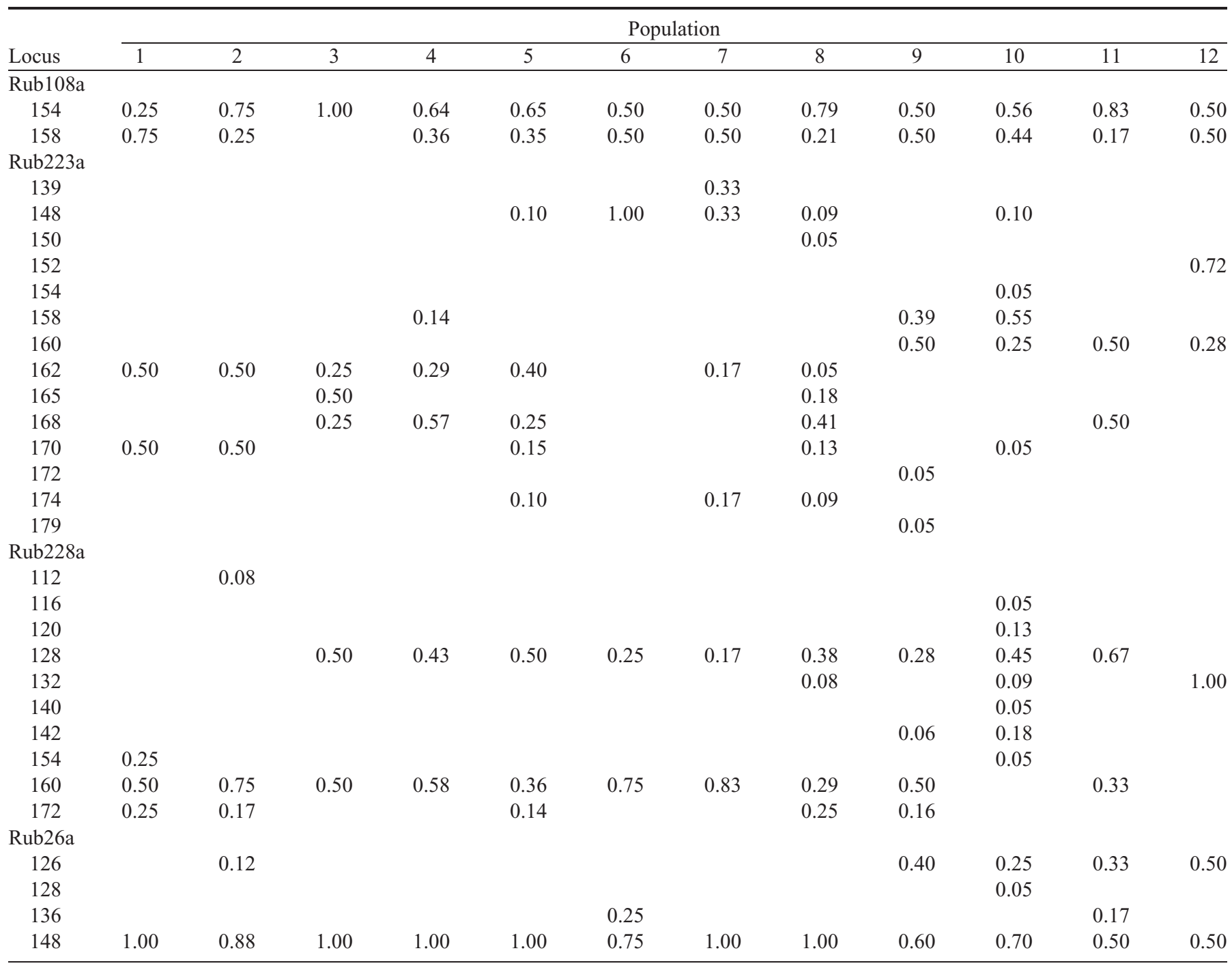

declined dramatically, with plants in some populations all but gone. Table 1 summarizes the changes in plant number at the 12 populations along with the altitude and flowering period at each site, which have been shown in previous studies to be important in limiting the possibilities of gene flow with plants at other populations. The reason for the decline in plant numbers at most populations was largely due to human intervention and included activities such as land excavations and sheep grazing. Only population 5 has shown an expansion in plant numbers over the 10-year period. This population in Glen Clova is in a wooded area with a stream on one side and a wall on the other, and is isolated within these two boundaries. In this population, vigorous root sucker production was observed, which led to new cane production. At populations 4 and 7 , where plant numbers were also declining, but where human intervention did not seem to be the cause, root sucker production was observed to a much lesser extent. Few fruit developed from plants in population 4 and no fruit development occurred from population 7, with flowers failing to proceed to fruit set.

SEed Germination. To determine the viability of the plants, seeds were counted and germinated from all individuals at Site
12. The plants at Site 12 were all at the same developmental stage, with ripe fruit production occurring within a few days across the whole site. The number of seeds per plant varied widely from no seeds (plants with no fruit) to 270 seeds per plant, with 26 of the 46 plants failing to produce fruit (data not shown). Similarly, seed germination varied from plant to plant and ranged from $0 \%$ to $84.6 \%$, although most were in the range $2 \%$ to $20 \%$, with an average germination of $12.8 \%$. Furthermore, there was no relationship between the number of seeds collected and germination rates. For example, of the 270 seeds collected from plant 12 , only 21 germinated. In contrast, only 13 seeds were collected from plant 21 and 11 germinated.

SuRVEY OF ALLELES ACROSS THE 12 POPULATIONS. Using 10 SSR loci (Table 2), 80 alleles were detected across all 117 wild individuals representing 12 populations. The number of alleles ranged from 2 (locus Rub277a) to 14 (locus Rub157b and locus Rub223a) for the wild accessions, with diversity values ranging from 0.025 (locus Rub277a) to 0.827 (locus Rub223a).

Among the five cultivated accessions analyzed (which represent the major cultivars over a time frame of almost 40 years), the number of alleles detected was lower for 8 of the 
10 loci, although the ranking among loci was very similar, with Rub157a amplifying the greatest number of alleles in both germplasm sets (Table 2). The two exceptions were at locus Rub108a where cultivars and wild samples contained alleles of 154 and $158 \mathrm{bp}$ and at locus Rub277a, where the cultivars contained alleles of 230,244 , and $250 \mathrm{bp}$, whereas the wild samples contained alleles of 230 and $242 \mathrm{bp}$.

Cluster analysis was performed using all of the wild individuals to determine whether individuals from the same site and geographical location grouped together (Fig. 1A). Marshall et al. (2001) show grid references and a map of the geographical range of these populations. Generally, individuals from the same region clustered. For example, all individuals from population 12 at Kingoodie grouped to a single cluster; similarly, the other lowland population at Knapp formed a single, tight cluster. The populations from higher altitudes, Glen Clova, Glen Doll, and Gella Bridge, clustered to a lesser extent with greater depth of branching (Fig. 1A). To compare between populations, cluster analysis was performed on a population similarity matrix (Fig. 1B). As expected, the

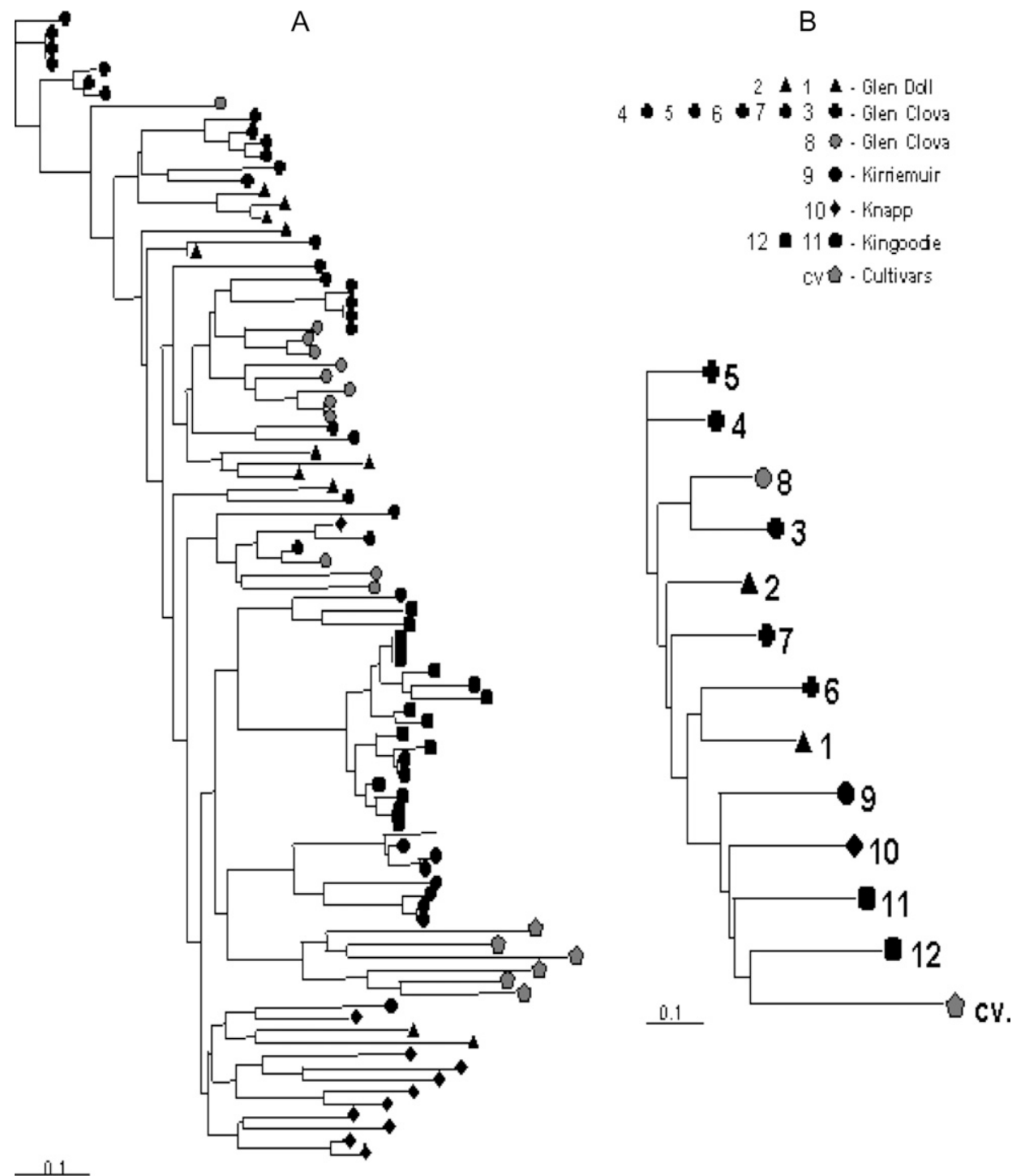

Fig. 1. Cluster analysis of 117 individuals from 12 wild Rubus idaeus populations in Scotland (A) and cluster analysis on a population similarity matrix (B) derived using 10 SSR loci. lowland populations form a cluster with the cultivated accessions, whereas the highland populations are more distinct and do not necessarily cluster.

Only seven alleles were shared across every population, although at most populations, these seven alleles were the most frequent (Table 4). Thirty-six alleles were unique to particular populations, and ranged in frequency from 0.02 to 0.600 , although the majority was low-frequency alleles. The number of alleles at each site and per locus clearly illustrates the genetic diversity present in the wild red raspberry plants sampled across most of the loci examined (Tables 2 and 3). The five commercial red raspberry cultivars generated 35 alleles, 17 of which were not found in the individuals analyzed in the wild populations. Five of the seven alleles found across all the wild populations also occurred in the cultivars. Two alleles, Rub223a-152bp and Rub262b-225bp, found only in the lowland wild populations (11 and 12) at an altitude of 5 $\mathrm{m}$ and growing within areas of red raspberry cultivation, were the same size as those found in the cultivated raspberries. Allele Rub223a-152bp was identified in 'Glen Moy' and is widespread at Site 12, and Rub262b-225bp in 'Glen Lyon' occurs in all individuals at populations 11 and 12 . Allele Rub4a-125bp, specific to population 10 in wild material, was also found in 'Glen Prosen'.

The observed heterozygosities at those populations with equal to or greater than 10 individuals were close to those expected for fully outbreeding populations in equilibrium within each site (Table 3 ). $F_{\text {IS }}$ values ranged from -0.521 in population 12 to 0.215 in population 8, but were not significant $(P>0.05)$. Highly negative $F_{\text {IS }}$ values indicate an excess of heterozygotes and are indicative of clonal growth in a population. However, of the 46 individuals studied in population 12, 13 multilocus genotypes (MLG) were found. Allelic variability was found in only five of the 10 loci examined; three loci (Rubla, Rub262b, and Rub26a) were fixed heterozygotes and two (Rub 227a and Rub228) were monomorphic in this population. Across all individuals and all loci, the global $F_{\text {IS }}$ value of $-0.117(P>0.99)$ indicates that red raspberry is an outbreeding species but that significant population differentiation exists [global $\left.F_{\mathrm{ST}}=0.348(P<0.001)\right]$.

Pairwise $F_{\mathrm{ST}}$ analysis was performed for the five populations containing equal to or more than 10 individuals (Table 5) and values ranged from 0.130 (between populations 5 and 8) to 0.482 (between populations 9 and 12). There was significant differentiation between all population pairs tested $(P<$ $0.05)$. 
Table 5. Pairwise $F_{\mathrm{ST}}$ values calculated for the five Scottish wild Rubus idaeus populations with more than 10 individuals.

\begin{tabular}{ccccc}
\hline & \multicolumn{4}{c}{ Population } \\
\cline { 2 - 5 } & 5 & 8 & 9 & 11 \\
\hline 8 & $0.130^{\mathrm{z}}$ & & & \\
9 & $0.251^{\mathrm{y}}$ & $0.336^{\mathrm{y}}$ & & \\
11 & $0.189^{\mathrm{y}}$ & $0.168^{\mathrm{y}}$ & $0.179^{\mathrm{y}}$ & \\
12 & $0.472^{\mathrm{y}}$ & $0.476^{\mathrm{y}}$ & $0.482^{\mathrm{y}}$ & $0.361^{\mathrm{y}}$ \\
${ }^{\mathrm{z} P<0.05 .}$ & & & & \\
${ }^{\mathrm{y}} P<0.001$. & & & & \\
& & & &
\end{tabular}

Analysis of Site 12 for gene flow. Population 12 runs in a right angle along the side of a country road and into a field along a railway embankment. Seed germination varied significantly from each parent (from $0 \%-84.6 \%$ ) and all plants that germinated from seeds were used for SSR analysis. Interestingly, no fruit set occurred on the first nine individuals at one end of the site and on individuals 29 to 45 , at the other end; only the middle clump (individuals 10-28) along with individual 46 at one end gave fruit and germinating seed. The 26 plants that did not produce fruit were not all clonal, and eight different MLGs could be identified across the 10 SSR loci. Figure 2 graphically represents the different MLGs across this site. The first nine nonfruiting individuals belonged to four different MLGs, which

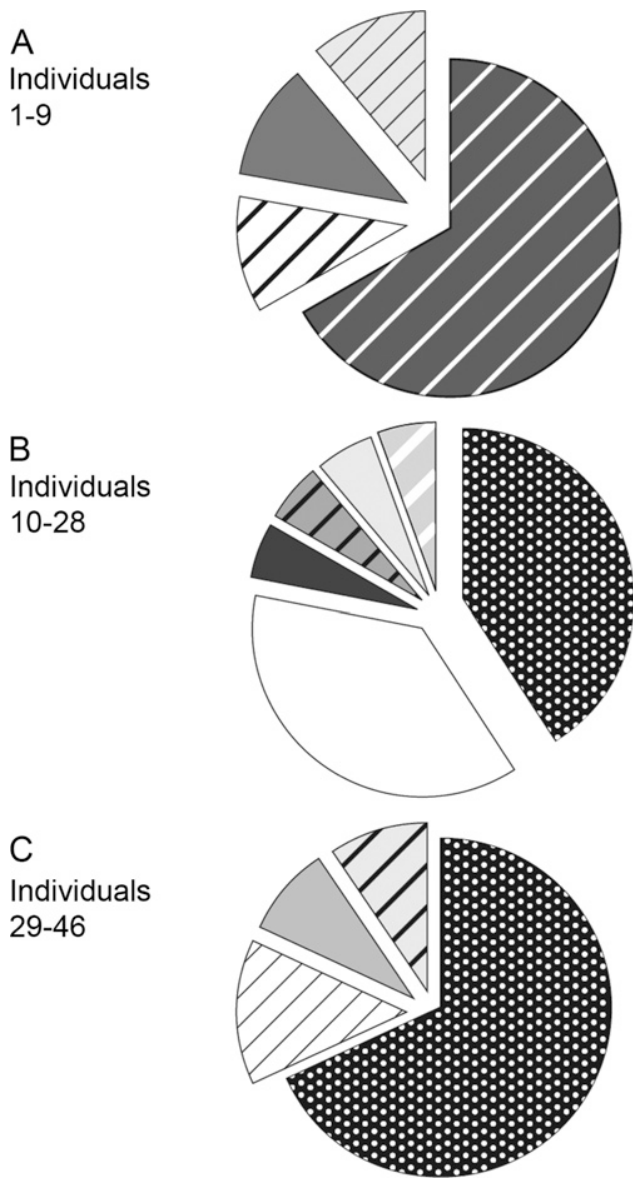

Fig. 2. Representation of the 13 multilocus genotypes (MLG) present in the 46 parental wild Rubus idaeus plants at Site 12 in Scotland. Individuals 1-9 (A) and 29-46 (except 46 C) did not produce fruit. Individuals 10-28 (B) all produced fruit. Segments with the same shading represent the same MLG. were different to the other MLGs found at the site and the most common MLG accounted for $66 \%$ of the individuals here (Fig. $2 \mathrm{~A})$. At the other end of the site, the other nonfruiting individuals belonged to four MLGs, one of which accounted for $68 \%$ of the individuals (Fig. 2C). The plants that did produce fruit could be assigned to six MLGs, one of which was common to the second clump of nonfruiting plants, and accounted for $42 \%$ of these fruiting individuals (Fig. 2B).

Of the 80 alleles identified across all populations, only 21 were present at population 12 , four of which were unique to this location. Thus, a further 59 alleles were identified in wild populations and 17 alleles in commercial cultivars that had the potential to enter population 12 through pollen flow detected in the progeny or by seedling recruitment from another population. Additional new alleles may also be present in red raspberry plants at this and other populations but were not captured by this analysis.

Analysis of the progeny revealed a total of 19 alleles, one of which (Rub228a-142) was new to population 12, having been absent from any of the parental plants (Fig. 3). In addition to the gain of this new allele, three alleles (Rub4a-115, Rub4a-145bp, and Rub25a-156bp) were lost from parents to progeny. The new allele occurred in the progeny from five maternal plants at Site 12 and suggests that pollinators entered the population with extrinsic pollen and distributed it around several plants.

No evidence of any other gene flow into Site 12 was found, though alleles shared with other populations may have entered the population but cannot be discriminated from those already present in this population. However, given the number of private alleles at each site, it is likely that shared alleles coming in from other populations would also bring in new alleles. The new allele (Rub228a-142bp) was found only in plants from lowland populations 9 (allele frequency $=0.06$ ) and 10 (allele frequency $=0.18$ ) at altitudes of 60 to $100 \mathrm{~m}$ and distances of 5 and $25 \mathrm{~km}$ but not from the plants analyzed at Site 11, which was geographically closest at $21 \mathrm{~m}$ and at the same altitude as Site $12(10 \mathrm{~m})$. The origin of the pollen carrying the Rub228a$142 \mathrm{bp}$ allele is uncertain, but it did not come from the populations studied here.

Disease PResenCe. RBDV was identified in plants at two populations, 9 and 10 . No evidence of red raspberry root rot was detected on any of the wild plants at any of the populations examined or from root material collected for propagation. Plants propagated from roots were subject to pot tests, and all material proved susceptible to root rot as defined by disease symptom production on roots, using 'Glen Moy' as a susceptible control for comparison (data not shown).

\section{Discussion}

Changes in the numbers of wild red raspberry plants at 12 populations have been determined over a 10 -year period with reductions in plant numbers observed. Given that each population had unique alleles that could be identified even in a small number of plants, this loss of plants will also equate to a loss of alleles. Earlier studies have demonstrated that plants from these locations, which span an altitudinal cline from 5 to $600 \mathrm{~m}$, exhibit significant variation in flowering and fruiting period when grown in a common environment (Marshall et al., 2001). Although this study has demonstrated that small populations currently have a comparable number of alleles with the larger populations, continued reduction in population 


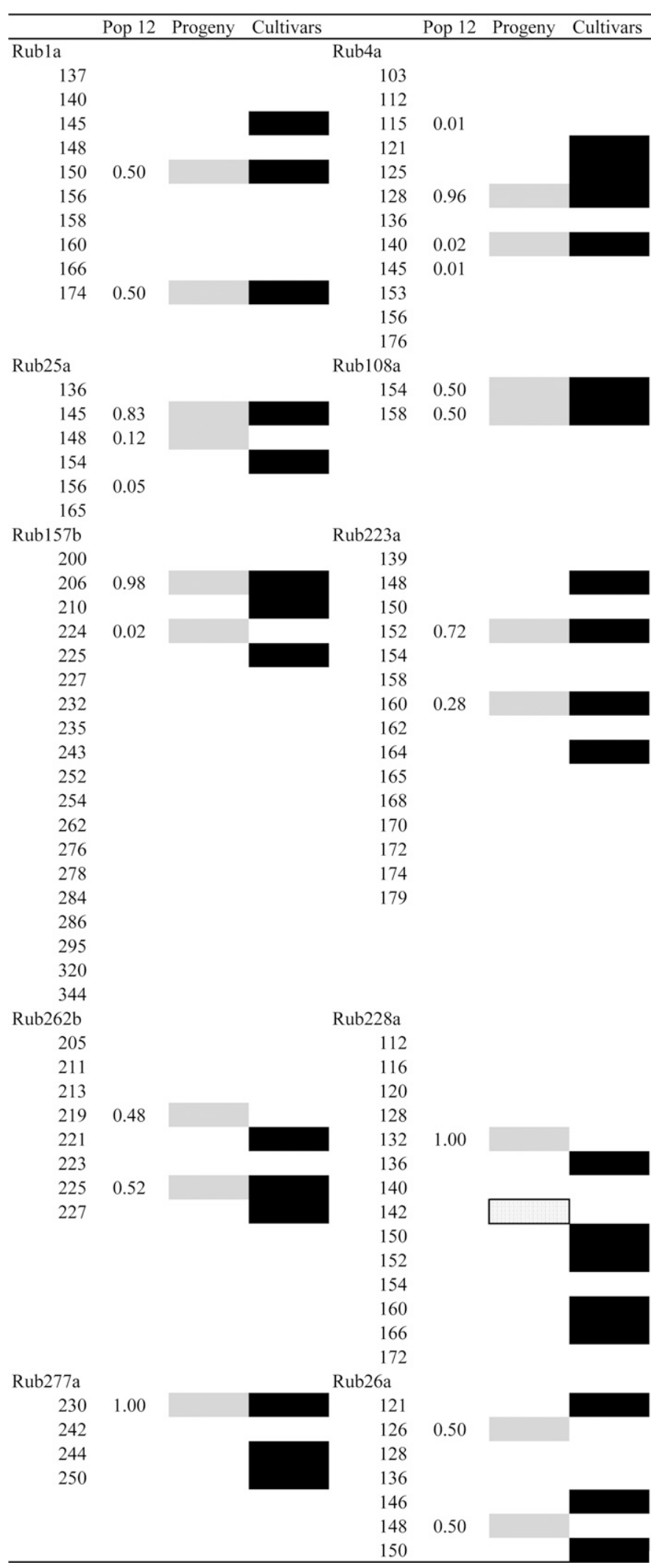

Fig. 3. Allele frequencies of parental wild Rubus ideaus plants at Site 12 (population 12) in Scotland, the alleles present in the progeny array at Site 12 (progeny), and the alleles present in five commercially grown $R$. idaeus cultivars at $10 \mathrm{SSR}$ loci. The patterned segment indicates the new allele present in the progeny array at Site 12 . size has been shown to severely reduce genetic diversity (Lowe et al., 2005). This may already be visible at Site 12 (Fig. 3) where plant numbers have dwindled from 150 to 46 over a 10 -year period. Following habitat disturbance and a reduction in population size, rare alleles tend to be lost first followed by the loss of more common alleles over several generations (Lande, 1988). Examination of the alleles present in the progeny at Site 12 reveals that three rare alleles have already been lost and that four of the 10 loci examined are virtually fixed, perhaps indicative of a decline in the number of common alleles.

Further loss of germplasm will have serious implications for long-term commercial red raspberry production, as well as for the sustainability of the natural populations, which also represent a valuable food source for wildlife. Most plant losses were readily explained by human impact, and, consequently, turnover of populations may take place over a relatively short cycle.

In populations 4 and 7, where no obvious human intervention was the cause of decline, differences in plant characteristics/physiology were determined. Roots of red raspberry have adventitious buds, most of which develop to form canes that then fruit in the following year. However, plants in population 4 exhibited little root sucker production, which in turn, would result in low cane numbers due to reduced vegetative propagation of the plants. Thus, the population would decline over time, especially as seedling recruitment had previously been shown to be low (Graham et al., 1997). It was possible that the serious root pathogen Phythopthora fragaria may have been the cause of the decline in root sucker production. However, this pathogen was not found here (and has not as yet been identified in areas not subject to commercial raspberry cultivation, D. Cooke, personal communication) and all material proved to be susceptible in subsequent pot tests, confirming symptom production would have been observed if the disease was present.

In population 7 where budbreak did occur but fruit development did not result, one possible explanation was the presence of RBDV, which leads to embryo abortion (Jones et al., 1998). Surveys of the 12 populations for RBDV, however, revealed the presence of the virus only at populations 9 and 10, and not at population 7 (Table 1). RBDV is a pollenborne pathogen and populations 9 and 10 have open flowers during the same time period (Table 1), which does not coincide with the flowering period at any of the other populations. The limited transmission of virus observed in these populations also suggests that limited pollen flow between wild red raspberry populations can occur. As the three individuals present at this site all had different multilocus genotypes, clonality of a nonfruiting genotype can be excluded. Although male sterile plants have been observed in European wild $R$. ideaus populations, neither male nor female sterile plants have been reported in UK populations (Keep, 1972). A reduction in reproductive output (fruit production and seed set) has been reported in fragmented tree populations (Lowe et al., 2005) due to reductions in the amount of compatible pollen entering the population. Another possible explanation for the lack of fruit development at population 7 could be due to mutation(s) in flowering/fruit set/fruit development genes in these plants, but the SSR markers employed here do not detect these differences.

Seed germination was very variable from plant to plant, most being in the range of $2 \%$ to $20 \%$. Only one plant showed significantly higher germination at $84.6 \%$. This low seed germination, in addition to the differences in open flower 
period previously shown (Table 1), may present a further barrier to gene flow and a loss of diversity. Evidence for this effect of seed germination was demonstrated at population 12 in the loss of three alleles from parents to progeny. The conditions under which seed germination is carried out are known to influence germination success (Bustamante et al., 1993; Figueiredo and Perin 1995; Rodriguez-Perez et al., 2005; Travest et al., 2001a, 2001b). Thus, the results under controlled conditions may not be directly comparable to events following direct fruit drop, or fruit ingestion by frugivores and then seed drop. However, a number of studies on seed germination have been carried out in Rubus. These have shown that regardless of variation in the germination rate that is sometimes, but not always, observed after ingestion, the final percentage of seed germination is not significantly greater than control germinations (Rodriguez-Perez et al., 2005; Travest et al., 2001a). Laskurain et al. (2004) studied seed production over a 4-year period on a number of shrubs, including Rubus, and seed production was found to be very poor. Although local seed banks for Rubus were found to be dense with a high number of seedling emergences every year, the survival of these seedlings was limited, with an average life of 7.4 months (Laskurain et al., 2004). As wild red raspberry plants fruit on second-year wood, these seedlings would not produce flowers and fruit in their first season, and the death of such seedlings therefore represents a loss of allelic diversity.

The maintenance of the levels of population differentiation observed (global $F_{\mathrm{ST}}=0.348$ ) in a bird-dispersed, fleshy fruited Rubus species initially seems surprising in the context of these forces for the homogenization of intraspecific variation. However, the absence of overlap in flowering period, limited fruit set, poor seed germination, and poor seedling establishment would certainly partially explain this. Gene flow by seed movement can be extensive in fleshy fruited plants. For example, in Iceland, redwings (Turdus iliacus) consume a range of late summer fruit immediately before undertaking long-distance migrations (Guitian et al., 1994), and the seeds of these fruit can be expected to disperse in quantity along the southeastern route taken by these thrushes. The effect of longdistance seed dispersal can be seen at a more local level. Fragmented relic populations of rowan trees (Sorbus acuparia) in southern Scotland exhibit high levels of intrapopulation diversity, thought to be maintained by efficient seed transport by frugivorous birds (Bacles et al., 2004).

Definitive evidence for gene flow into a site via pollen was collected in this study with the presence of one new allele in the progeny arising from five parent plants at Site 12 (Fig. 3). From the codominant SSR marker system, direct observations on the level of heterozygosity were made and these are consistent with red raspberry being an outbreeding species (Keep, 1972). Some degree of clonality was found in these populations, but the extent of this has been found to be limited in other wild $R$. idaeus populations (Antonius and Nybom, 1994). Given the allele frequency within each population, it appears that the heterozygosity observed is not significantly different from that expected and is supported by the nonsignificant $F_{\text {IS }}$ values observed. Therefore, the values here are consistent with a random mating model within populations with strong barriers to self-fertilization. The close match of observed SSR heterozygosity to that expected from the allele diversity within populations suggests that the alleles present in populations are being maintained through sexual generations and therefore inbreeding depression and genetic differentiation through inbreeding are unlikely. However, study of progeny arrays demonstrated a loss of the total number of alleles from parents to progeny. In addition, Fig. 3 represents the frequency of alleles found across the 10 loci at Site 12 and it can be seen that of the 10 loci examined, six are almost fixed in the parental material.

Examination of the 10 loci in five cultivated raspberries revealed 35 alleles, of which 18 occurred in the wild plants. Sixty-two alleles detected in the wild plants were not present in cultivated raspberries and hence represent an example of the potential biodiversity that may be useful in future breeding. For example, plants derived from seeds collected from wild red raspberry populations at high altitude $(>500 \mathrm{~m})$ demonstrate greater resistance to powdery mildew (Sphaerotheca macularis) than plants from lower altitudes (Keep, 1972). The challenge is to identify the genes that will be useful from wild germplasm and incorporate them into breeding programs for sustainable red raspberry production in the future.

The use of SSRs in population studies assumes that the loci examined are the same, and that the polymorphisms leading to variation in allele sizes are within the repeat. Despite the large size range of alleles at some loci (ranging from 200 to $344 \mathrm{bp}$ at locus Rub157b for example), the limited sequence analysis performed here (data not shown) demonstrates that the same locus was amplified in each population. Although the SSR repeat is the main site of length variation, other polymorphisms were also identified. Whether this level of sequence polymorphism within the SSR and the flanking sequence identified at this locus is unusual or typical in red raspberry needs further investigation. However, it is possible that considerably more genetic diversity exists within the populations than is detected by size variations alone. It is also reassuring that the SSR loci appear to have not diverged recently, and that there is little likelihood of reversion events confusing the analysis.

The data generated for the 46 individuals at Site 12 in this study were compared with the previous RAPD analysis (Graham et al., 2003). Based on RAPD data, the similarities of individuals at Site 12 varied from $79 \%$ to $100 \%$ with a mean of $87 \%$. With SSR markers, lower similarities ranging from 50\% to $97 \%$ with a mean of $62 \%$ were determined (data not shown). The overall pattern across all populations reflects that of population 12, with SSRs giving higher values for genetic diversity. There is nevertheless a significant association and correlation between the two methods in estimating interplant similarities.

In summary, the SSRs confirm that these wild red raspberry populations are of mixed but similar and not purely clonal genotypes. This study provides evidence that red raspberry is outbreeding, but patterns of seedling recruitment and pollen flow inferred from the data suggest that aspects of the breeding biology of this species restrict gene flow, especially between populations (global $F_{\mathrm{ST}}=0.348$ ). Adaptation to local conditions may also play a role in maintaining distinct populations, and selection for local adaptation may be a stronger force than previously realized in maintaining differentiation.

In light of current change to the natural environment, including climate and disease pressures, these populations represent a potentially useful germplasm resource. As our understanding of genes controlling important traits in red raspberry improves, these populations may eventually provide a source of locally adapted alleles for use within commercial red raspberry breeding programs to develop new, high-quality 
cultivars, better suited to the environment, an approach being used in other crops (e.g., Kaur et al., 2008).

\section{Literature Cited}

Antonius, K. and H. Nybom. 1994. DNA fingerprinting reveals significant amounts of genetic variation in a wild red raspberry Rubus idaeus population. Mol. Ecol. 3:177-180.

Bacles, C.F.E., A.J. Lowe, and R.A. Ennos. 2004. Genetic effects of chronic habitat fragmentation on tree species: The case of Sorbus aucuparia in a deforested Scottish landscape. Mol. Ecol. 13:573-584. Bustamante, R.O., J.A. Simonetti, and J.E. Mella. 1993. Are foxes legitimate and efficient seed dispersers. Acta Oecol. 13:203-208.

Dawson, I.K., R. Waugh, A.J. Simons, and W. Powell. 1997. Simple sequence repeats provide a direct estimate of pollen mediated gene dispersal in the tropical tree Gliricidia sepium. Mol. Ecol. 6:179-183. Estoup, A., F. Rousset, Y. Michalakis, J.M. Cornuet, M. Adriamanga, and R. Guyomard. 1998. Comparative analysis of microsatellites and allozyme markers: A case study investigating microgeographic differentiation in brown trout (Salmo trutta). Mol. Ecol. 7:339-353.

Felsenstein, J. 2004. Phylogeny inference package. 2 Oct. 2008. $<$ http://evolution.genetics.washington.edu/phylip.html $>$.

Figueiredo, R.A. and E. Perin. 1995. Germination ecology of Ficus luschnathiana drupelets after bird and bat ingestion. Acta Oecol. 16:71-75.

FitzSimmons, N.N., C. Moritz, and S.S. Moore. 1995. Conservation and dynamics of microsatellite loci over 300 million years of marine turtle evolution. Mol. Biol. Evol. 12:432-440.

Goudet, J. 2002. FSTAT, a program to estimate and test gene diversities and fixation indices (version 2.9.3.). 7 Apr. 2008. $<\mathrm{http}$ :// www2.unil.ch/popgen/softwares/fstat.htm>.

Graham, J., G.R. Squire, B. Marshall, and R.E. Harrison. 1997. Spatially dependent genetic diversity within and between colonies of wild raspberry Rubus idaeus detected using RAPD markers. Mol. Ecol. 6:272-281.

Graham, J., B. Marshall, and G. Squire. 2003. Genetic differentiation over a spatial environmental gradient in wild Rubus idaeus populations. New Phytol. 157:667-675.

Graham, J., K. Smith, I. Tierney, K. MacKenzie, and C. Hackett. 2006. Mapping gene $H$ controlling cane pubescence in red raspberry and its association with resistance to cane botrytis and spur blight, rust and cane spot. Theor. Appl. Genet. 112:818-831.

Graham, J., K. Smith, K. MacKenzie, L. Jorgenson, C. Hackett, and W. Powell. 2004. The construction of a genetic linkage map of red raspberry (Rubus idaeus subsp. idaeus) based on AFLPs, genomicSSR and EST-SSR markers. Theor. Appl. Genet. 109:740-749.

Graham, J., K. Smith, M. Woodhead, and J. Russell. 2002. Development and use of SSR markers in Rubus species. Mol. Ecol. Notes 2:250-252.

Granstrom, A. 1987. Seed variability of fourteen species during five years of storage in a forest soil. J. Ecol. 75:321-331.

Guitian, J., I. Munilla, P. Guitian, and B. Lopez. 1994. Frugivory and seed dispersal by redwings Turdus iliacus in southwest Iceland. Ecography 17:314-320.

Jennings, D.L. 1988. Raspberries and blackberries: Their breeding, diseases and growth. Academic Press, London.

Jones, A.T., W.J. McGavin, M.A. Mayo, and J. Graham. 1998. Natural infection with red raspberry bushy dwarf virus (RBDV) of the putatively RBDV-resistant red raspberry cultivar Glen Moy, and the demonstration that it does not contain the RBDV resistance gene Bu. Ann. Appl. Biol. 133:403-414.

Kaur, N., K. Street, M. Mackay, N. Yahiaoui, and B. Keller. 2008. Molecular approaches for characterization and use of natural disease resistance in wheat. Eur. J. Plant Pathol. 121:387-397.

Keep, E. 1972. Variability in the wild raspberry. New Phytol. 71:915-924.

Kennedy, D.M. and J.M. Duncan. 1991. Methods for assessing the resistance of red raspberry genotypes to Phytophthora root-rot. Plant Pathol. 40:387-394.
Lande, R. 1988. Genetics and demography in biological conservation. Science 241:1455-1460.

Laskurain, N.A., A. Escudero, and J.M. Olano. 2004. Seedling dynamics of shrubs in a fully closed temperate forest: Greater than expected. Ecography 27:650-658.

Legave, J.M., I. Farrera, T. Almeras, and M. Calleja. 2008. Selecting models of apple flowering time and understanding how global warming has had an impact on this. J. Hort. Sci. Biotechnol. $83: 76-84$.

Lowe, A.J., D. Boshier, M. Ward, C.F.E. Bacles, and C. Navarro. 2005. Genetic resource impacts of habitat loss and degradation: Reconciling empirical evidence and predicted theory for neotropical trees. Heredity 95:255-273.

Macaulay, M., L. Ramsay, W. Powell, and R. Waugh. 2001. A representative, highly informative 'genotyping set' of barley SSRs. Theor. Appl. Genet. 102:801-809.

Marshall, B., R.E. Harrison, J. Graham, J.W. McNicol, G. Wright, and G. Squire. 2001. Spatial trends of phenotypic diversity between colonies of wild raspberry Rubus idaeus. New Phytol. 151:671682.

Nei, M. 1973. Analysis of gene diversity in subdivided populations. Proc. Natl. Acad. Sci. USA 70:3321-3323.

Paetkau, D., W. Calvert, I. Stirling, and C. Strobeck. 1995. Microsatellite analysis of population structure in Canadian polar bears. Mol. Ecol. 4:347-354.

Page, R.D.M. 1996. TREEVIEW: An application to display phylogenetic trees on personal computers. Comput. Appl. Biosci. 12:357358.

Park, S.D.E. 2001. Trypanotolerance in West African cattle and the population genetic effects of selection. University of Dublin, Dublin, Ireland, PhD Thesis.

Perera, L., J. Russell, J. Provan, and W. Powell. 2000. Use of microsatellite DNA markers to investigate the level of genetic diversity and population genetic structure of coconut (Cocos nucifera L.). Genome 43:15-21.

Powell, W., G.C. Machray, and J. Provan. 1996. Polymorphism revealed by simple sequence repeats. Trends Plant Sci. 1:215-222.

Rodriguez-Perez, J., N. Riera, and A. Travest. 2005. Effect of seed passage through birds and lizards on emergence rate of Mediterranean species: Differences between natural and controlled conditions. Funct. Ecol. 86:85-95.

Ritland, K. 1986. Joint maximum likelihood estimation of genetics and mating structure using open pollinated progenies. Biometrics 42: $25-43$.

Simonsen, B.T., H.R. Siegismund, and P. Arctander. 1998. Population structure of African buffalo inferred from mtDNA sequences and microsatellite loci: High variation but low differentiation. Mol. Ecol. 7:225-237.

Stanford University. 2004. Microsat. 1 Sept. 2008. <http://hpgl.stanford. edu/projects/microsat/>.

Travest, A., N. Riera, and R.E. Mas. 2001b. Passage through bird guts causes interspecific differences in seed germination characteristics. Funct. Ecol. 15:669-675.

Travest, A., T. Bermejo, and M. Wilson. 2001a. Effect of manure composition on seedling emergence and growth of two common shrub species of southeast Alaska. Plant Ecol. 155:29-34.

Vendramin, G.G., M. Anzidei, A. Madaghiele, C. Sperisen, and G. Bucci. 2000. Chloroplast microsatellite analysis reveals the presence of population subdivision in norway spruce (Picea abies K.). Genome 43:68-78.

Ward, M., C.W. Dick, R. Gribel, and A.J. Lowe. 2005. To self or not to self... A review of outcrossing and pollen-mediated gene flow in neotropical trees. Heredity 95:246-254.

Young, A., T. Boyle, and A.H.D. Brown. 1996. The population genetic consequences of habitat fragmentation for plants. Trends Ecol. Evol. 11:413-418. 